\title{
Effects of comprehensive geriatric assessment on physical fitness in an acute medical setting for frail elderly patients
}

\author{
Kristina Åhlund ${ }^{1,2}$ \\ Maria Bäck 2,3 \\ Birgitta Öberg ${ }^{2}$ \\ Niklas Ekerstad ${ }^{4,5}$ \\ 'Department of Physiotherapy, \\ NU Hospital Group, Trollhättan, \\ ${ }^{2}$ Department of Medical and Health \\ Sciences, Division of Physiotherapy, \\ Linköping University, Linköping, \\ ${ }^{3}$ Department of Occupational Therapy \\ and Physiotherapy, Sahlgrenska \\ University Hospital, Gothenburg, \\ ${ }^{4}$ Department of Cardiology, \\ NU Hospital Group, Trollhättan, \\ ${ }^{5}$ Department of Medical and Health \\ Sciences, Division of Health Care \\ Analysis, Linköping University, \\ Linköping, Sweden
}

This article was published in the following Dove Press journal:

Clinical Interventions in Aging

13 November 2017

Number of times this article has been viewed

Introduction: Frail elderly people often use emergency care. During hospitalization, physical decline is common, implying an increased risk of adverse health outcomes. Comprehensive Geriatric Assessment (CGA) has been shown to be beneficial for these patients in hospital care. However, there is very limited evidence about the effects on physical fitness. The aim was to compare effects on physical fitness in the acute care of frail elderly patients at a CGA unit versus conventional care, 3 months after discharge.

Patients and methods: A clinical, prospective, controlled trial with two parallel groups was conducted. Patients aged $\geq 75$ years, assessed as frail and in need of inpatient care, were assigned to a CGA unit or conventional care. Measurements of physical fitness, including handgrip strength (HS), timed up-and-go (TUG), and the 6-minute walk test (6-MWT) were made twice, at the hospital index care period and at the 3-month follow-up. Data were analyzed as the mean change from index to the 3-month follow-up, and dichotomized as decline versus stability/improvement in physical fitness.

Results: In all, 408 participants, aged $85.7 \pm 5.4$ years, were included. The intervention group improved significantly in all components of physical fitness. The controls improved in TUG and declined in HS and 6-MWT. When the changes were dichotomized the intervention group declined to a lesser extent; HS $p<0.001$, 6-MWT $p<0.001$, TUG $p<0.003$. The regression analysis showed the following odds ratios (ORs) for how these outcomes were influenced by the intervention; HS OR 4.4 (confidence interval [CI] 95\% 2.2-9.1), 6-MWT OR 13.9 (CI 95\% 4.2-46.2), and TUG OR 2.5 (CI 95\% 1.1-5.4).

Conclusion: This study indicates that the acute care of frail elderly patients at a CGA unit is superior to conventional care in terms of preserving physical fitness at 3 months follow-up. CGA management may positively influence outcomes of great importance for these patients, such as mobility, strength, and endurance.

Keywords: frail elderly, comprehensive geriatric assessment, physical fitness, outcomes

\section{Introduction}

Old people with multimorbidity and disability are frequent visitors to acute medical hospital departments. ${ }^{1}$ In this group of patients, admissions are often inevitable, they often require a longer length of stay compared with their younger counterparts, and the readmission rate is high. ${ }^{2-5}$ Frailty is a clinical syndrome reflecting the dependence and vulnerability of these people. ${ }^{6}$ There are different ways to define frailty. The phenotype model of frailty defined by Fried et $\mathrm{al}^{7}$ demonstrates predictive validity for the adverse outcomes that frail elderly people run the risk of experiencing, such as falls, hospitalizations, disability, institutionalization, and death. According to this definition,
Correspondence: Niklas Ekerstad Department of Cardiology, NU (NÄL-Uddevalla) Hospital Group, Lärketorpsvägen, 46100 Trollhättan, Sweden $\mathrm{Tel}+46736249652$ Fax +46 I0 4357129 Email niklas.ekerstad@vgregion.se (c) (1) (2) 2017 Åhlund et al. This work is published and licensed by Dove Medical Press Limited. The full terms of this license are available at https://www.dovepress.com/terms.php
and incorporate the Creative Commons Atribution - Non Commercial (unported, v3.0) License (http://creativecommons.org/licenses/by-nc/3.0/). By accessing the work you BY NC and incorporate the Creative Commons Attribution - Non Commercial (unported, v3.0) License (http:///creativecommons.org/licenses/lby-nc/3.0/). By accessing the work you
hereby accept the Terms. Non-commercial uses of the work are permitted without any further permission from Dove Medical Press Limited, provided the work is properly attributed. For permission for commercial use of this work, please see paragraphs 4.2 and 5 of our Terms (https://www.dovepress.com/terms.php). 
a person is considered frail when three or more of the following criteria are present: weakness (eg, low handgrip strength [HS]), poor endurance, slow walking speed, low physical activity, and shrinking. Another way to describe frailty is by the accumulation of deficits. ${ }^{8}$

Physical function describes a person's capacity to carry out the physical activities of daily living (ADL). ${ }^{9}$ Physical fitness comprises a set of measurable health- and skill-related outcomes, such as cardiorespiratory endurance, muscle strength, muscle endurance, and balance..$^{10}$ The relationship between frailty and physical fitness is evident and frailty is often said to herald physical decline. ${ }^{11}$ Age-related muscle loss, sarcopenia, is one key component of the frailty syndrome and it negatively affects physical fitness. ${ }^{12,13}$

In a recently published study, physical fitness was measured objectively and found to be severely impaired in acutely hospitalized frail elderly patients. ${ }^{14}$ It is well known that frail elderly patients risk further deterioration in connection with hospital care and the recovery rate appears to be low., ${ }^{5}-19$ A decrease in physical fitness is associated with an increased risk of disability and dependence ${ }^{20}$ and it negatively affects the ability to benefit from medical interventions, which worsens the prognosis still further. ${ }^{13,21-26}$ However, previous research indicates that it may be possible to reverse frailty. ${ }^{27}$ It is therefore of utmost interest to identify frailty in order to prevent, reduce, and postpone adverse health consequences. $^{28}$

Today, the conventional acute medical ward is usually a specialized, organ-specific unit with the goal of providing care according to national and international guidelines adapted for specific diseases. Studies have shown that frail, multimorbid, and disabled patients are likely to benefit from a more holistic approach. ${ }^{29,30}$ In the context of hospital care, a health care model called Comprehensive Geriatric Assessment (CGA) has been shown to be consistently beneficial regarding mortality, disability, and cognitive functions. ${ }^{31}$ The CGA concept involves early identification of persons at the greatest risk of complications and adverse health outcomes..$^{32}$ The initial purpose of CGA was to plan and/or deliver medical, psychosocial, and rehabilitative care and the model is defined as a

multidimensional interdisciplinary diagnostic process intended to determine a frail elderly person's medical, psychological and functional capabilities and limitations, in order to develop an overall plan for treatment and longterm follow-up. ${ }^{33}$

It explicitly involves an early-rehabilitation perspective. ${ }^{34}$
Previous studies have concluded that CGA implies functional benefits, in terms of ADL, for elderly patients with acute medical or orthopedic disorders, compared with conventional care. ${ }^{34-37}$ To our knowledge, there is no study which has objectively investigated how CGA in an acute medical setting specifically affects physical fitness, in severely frail elderly patients.

\section{Aim}

The aim was to compare the effects on physical fitness in the acute care of frail elderly patients at a CGA unit versus conventional care, 3 months after discharge.

\section{Patients and methods Design and setting}

This is a clinical prospective controlled trial with two parallel groups carried out at the NÄL-Uddevalla (NU) Hospital Group, in western Sweden. The total population of the NU health care system is 280,000 inhabitants. The study was approved by the regional ethical review board in Gothenburg (Dnr: 8883-12, December 12, 2012) and registered at the Swedish National Database of Research and Development; identifier 113021 (http://www.researchweb.org/is/vgr/ project/113021).

\section{Participants}

The study population was frail elderly patients included in the research project entitled "Is the treatment of frail elderly patients effective in an elderly care unit". The inclusion criteria were patients $\geq 75$ years, assessed to be in acute need of inhospital treatment and frail according to the FRail Elderly Support researcH group (FRESH) screening instrument. ${ }^{38,39}$ A patient clearly suited for care at an organ-specific medical unit, for example, patients with acute myocardial infarction, sepsis, or acute stroke, were excluded from the study, as were patients whose informed consent could not be obtained.

\section{Data collection}

The data collection has previously been described by Ekerstad et $\mathrm{al}^{40}$ and is therefore only briefly described. When the staff at the ambulance or the primary health care center identified a patient who met the inclusion criteria, they phoned a senior physician at the CGA unit or, if it was at night, the on-call physician. If the physician agreed that the patient fulfilled the inclusion criteria of the study protocol and there was a bed available at the CGA unit, the patient was admitted there directly and allocated to the intervention group. If no bed 
was available at the CGA unit, the patient was admitted to a conventional acute medical ward via the emergency room and allocated to the control group. As soon as possible after admission, written informed consent was obtained. A few patients were cognitively impaired and informed consent was then given by a next of kin, through proxy consent. When proxy consent via a next of kin could not be given, cognitively impaired patients were not included.

\section{Procedure}

The participants performed the physical performance tests twice - first, before discharge from the index hospital stay and then at the 3-month follow-up visit at hospital or in the patient's home. In many previous studies of elderly patients, measurements were done at 3-month follow-up, ${ }^{29,35}$ which can be considered to be an appropriate point regarding follow-up of these patients. In addition, the FRESH screening instrument ${ }^{38,39}$ and Charlson's comorbidity index $(\mathrm{CCI})^{41}$ were administered at these time points. Clinical and demographic characteristics were documented and taken from the patient's medical records and by questioning the patient or his/her next of kin.

The tests were carried out by experienced physical therapists or physicians who had all been trained and informed in a group about the test procedure before the data collection started and then repeatedly during the study. Because of the participants' condition, it was not possible to standardize the day of testing. The intention was to perform the initial tests during the latter part of the hospital stay, before discharge.
In both study groups, standard diagnostic and therapeutic procedures were undertaken according to national and international guidelines. For both groups, this included bedside medical examinations, laboratory testing, X-ray examinations, electrocardiograms, medical referrals, nutritional therapy, blood transfusions, and oral or parenteral drug treatment.

\section{Intervention}

The intervention was acute medical care at a CGA unit (in Swedish Medicinsk ÄldreVårdsAvdelning [MÄVA]). Table 1 provides a comparison with conventional care. There are two CGA units in the NU Hospital Group which, in addition to care in accordance with guidelines, are characterized by a structured, systematic interdisciplinary CGA and care via validated instruments and evidence-based procedures. The CGA units at the hospital involve a person-centered approach and work in close collaboration with other health care providers in the municipalities and primary health care. Patients can be admitted directly without passing through the emergency room. At the CGA units, physical therapists and occupational therapists work as members of the team, close to other professions in the ward. These professionals implement a structured early-rehabilitation strategy and, soon after admission, every patient is assessed regarding ADL, walking ability, balance, and the need for assistive devices to find the best treatment for each patient. Information is usually given to patients and their relatives to reduce the risk of concern and uncertainty related to the risk of decline in physical activity. A team conference is held every day, enabling all the

Table I Comparison of management in the intervention group (CGA) and control group (conventional acute medical care)

\begin{tabular}{|c|c|c|}
\hline & Comprehensive geriatric assessment and care & Conventional acute medical care \\
\hline Department and facilities & $\begin{array}{l}\text { Two MÄVA (acute elderly care CGA units) wards with a total } \\
\text { of } 48 \text { beds; one, two, or four-bed rooms }\end{array}$ & $\begin{array}{l}\text { Wards of internal and emergency medicine; one, } \\
\text { two, or four-bed rooms }\end{array}$ \\
\hline & Division of Internal Medicine and Emergency Care & Division of Internal Medicine and Emergency Care \\
\hline \multicolumn{3}{|l|}{ Team members } \\
\hline Physicians & $\begin{array}{l}\text { Yes. Specialists in internal medicine, family medicine and/or } \\
\text { geriatrics }\end{array}$ & Yes. Specialists in internal medicine \\
\hline Licensed practical nurses & Yes. Including specialized admission and discharge nurses & Yes \\
\hline Occupational therapists & Yes & No. Only counseling \\
\hline Physiotherapists & Yes & No. Only counseling \\
\hline Nutritionists & No. Only counseling & No. Only counseling \\
\hline Treatment & $\begin{array}{l}\text { Systematic, structured interdisciplinary comprehensive } \\
\text { geriatric assessment and care by validated instruments focusing } \\
\text { on: somatic and mental health, medication review, functional } \\
\text { and activity ability including early rehabilitation, social situation } \\
\text { Early discharge planning }\end{array}$ & $\begin{array}{l}\text { Following routines at departments of internal } \\
\text { medicine and emergency care in accordance with } \\
\text { guidelines }\end{array}$ \\
\hline Admission route & Directly to the MÄVA ward via ambulance or primary care & Via the emergency ward \\
\hline
\end{tabular}

Notes: For both groups, standard management procedures in accordance with national and international guidelines were followed. Copyright () 20I7. Dove Medical Press. Reproduced from Ekerstad N, Karlson BW, Dahlin Ivanoff S, et al. Is the acute care of frail elderly patients in a comprehensive geriatric assessment unit superior to conventional acute medical care? Clin Interv Aging. 2017; I 2: I-9.40

Abbreviations: CGA, Comprehensive Geriatric Assessment; MÄVA, Medicinsk ÄldreVårdsAvdelning. 
professions in the ward to share information and experiences, in order to use a more consistent, person-centered approach toward each patient with one of the goals of keeping the patient ambulatory and independent, to the greatest extent possible. Although the patients did not receive homework tasks, for example, via recording charts, there were indeed educational moments in the intervention, including advice regarding physical exercise after discharge.

\section{Control group}

The patients in the control group were treated at conventional acute medical care units, where standard procedures according to national and international guidelines were followed. All the patients were admitted to these medical care units via the emergency room. From these wards, care planning was performed prior to discharge, via the hospital's central care planning unit. Physical therapists and occupational therapists are also linked to each of these medical care units, but, at these units, these professionals use a more consultative approach and only see patients after being actively contacted by physicians or nurses. The physical therapists or occupational therapists are not involved in any regular team meetings at the conventional acute medical care units.

\section{Measurements}

\section{Frailty}

Frailty was assessed using the FRESH screening instrument, ${ }^{38,39}$ which is a validated screening instrument that has been shown to be appropriate in an emergency hospital setting. It consists of five questions relating to tiredness, falls, endurance, needing support while shopping, and three or more visits to the emergency department in the past 12 months. If two or more of these questions were answered with a yes, the patient was considered to be frail. FRESH has been shown to have greater sensitivity (84\%) and slightly lower specificity (75\%) compared with the frailty phenotype indicators. ${ }^{38}$ FRESH screening was performed by a physician or a nurse by the time of inclusion. At the 3-month follow-up, it was performed by the assessing physician. Information was received by interviewing the patient or his/her next of kin and from the patient's medical records.

\section{Comorbidity}

$\mathrm{CCI}^{41}$ is a frequently used measurement of the total burden of comorbidities. It consists of 19 comorbidities, each of which is given a severity weighting depending on the risk of dying associated with this condition. The CCI shows the sum of weighted items with a score between 0 and 10 and predicts the mortality for a patient. The CCI was completed from medical records by the assessing physician before discharge and at the 3-month follow-up.

\section{Physical fitness}

In relation to previously described frailty indicators, three different tests were performed to measure physical fitness: HS, functional mobility, and submaximal aerobic capacity.

\section{HS}

A hydraulic hand dynamometer (Saehan Corporation, Masan, Republic of Korea) with a grip position that could be adapted to suit each individual was used for measuring HS. The patient performed the test in a sitting position with the hand next to the body, the shoulder joint in a neutral position, the elbow flexed at $90^{\circ}$, and the wrist in a neutral position..$^{42}$ The patient was instructed to squeeze his/her dominant hand as hard as possible and then relax. The outcome is the peak value ( $\mathrm{kg}$ ) of three attempts, with a short rest (about 1 minute) between each try. If the patient was not able to sit, he/she was allowed to lie in bed with the head end raised and the elbow supported. This test has been shown to have good validity when measuring muscle strength and good test-retest reliability in community-dwelling elderly and in older persons with dementia $(\mathrm{ICC}=0.97) .{ }^{42,43}$

\section{Functional mobility}

The timed up-and-go test (TUG) measures the time spent, in seconds, when a patient rises from a standard armchair $(\sim 46 \mathrm{~cm})$, walks $3 \mathrm{~m}$, turns around and walks back to the chair again. The 3-m distance should be clearly marked with tape that deviates from the floor color. ${ }^{44}$ In this study, the patients were instructed to walk as quickly and as safely as possible and walking aids were allowed. The TUG is an instrument with good test-retest reliability (ICC $=0.99$ ) in frail elderly adults. In community-dwelling elderly adults, it has been shown to be a valid measurement of functional mobility and correlates well with gait speed (Pearson's $r=0.75$ ), ADL (Pearson's $r=-0.79$ ), and balance (Pearson's $r=-0.72$ ). ${ }^{44,45}$

\section{Submaximal aerobic capacity}

The 6-minute walk test (6-MWT) measures the total distance, in meters, during a 6-minute walk. The person walks back and forth along a 30-m corridor with markings every $5 \mathrm{~m},{ }^{46}$ after an instruction to walk as far as possible during 6 minutes. In the present study, the patients were allowed to stop and continue during the test, but the test was interrupted if the patient was unable to continue, mostly due to dyspnea and 
strong dizziness. Walking aids were allowed. The 6-MWT is a test with good test-retest reliability ( $\mathrm{ICC}=0.95$ ) for community-dwelling elderly ${ }^{45}$ and is commonly used to measure submaximal functional exercise capacity in patients with cardiorespiratory diseases. ${ }^{46}$

\section{Analysis}

The sample size calculation (Sample Size Calculator; ClinCalc LLC, Arlington Heights, IL, USA) was based on the primary outcome decline in ADL (Katz index) from baseline to 3 months after discharge. No previous study with an identical primary variable (different follow-up times) was found. However, one similar study was found, ${ }^{47}$ which focused on the ADL function in less frail patients during hospitalization. Using a two-sided test, $80 \%$ power, and a significance level of $\alpha=0.05$, it was necessary to include 150 patients in each study group. To compensate for the uncertainty, due to longer follow-up times which may reduce the difference in ADL decline, that is, expected reduction of treatment effect size, it was estimated that 200 patients in each study group, 400 in total, had to be included.

The data were computerized and analyzed using the Statistical Package for Social Sciences (IBM SPSS Statistics for Windows, version 22.0; IBM Corporation, Armonk, NY, USA). Student's $t$-test was used to compare continuous, parametric data between the groups and the chi-square test was used to compare categorical data. The 0- to 3-month changes were calculated first as the mean change and standard deviation for each group, after which they were dichotomized as decline versus stability/improvement. Adjustments for possible differences at baseline were made, using logistic regression models. Age, gender, CCI score, and the baseline value of measurement were counted as covariates in these models.

An intention-to-treat principle was followed.

\section{Results \\ Baseline characteristics of the study population}

From March 2013 to July 2015, a total of 419 evaluable patients were randomized of whom 408 patients were evaluable; 206 in the intervention group (CGA unit) and 202 in the control group (conventional care) (Figure 1).

Their mean age was $85.7 \pm 5.4$ years and $56 \%$ were female. There were no significant differences between the groups regarding age, gender, degree of frailty, or percentage living alone. Both groups were heavily affected by diseases, particularly renal impairment and cardiovascular disease. The intervention group had a slightly higher comorbidity burden (CCI $7.4 \pm 2.1$ vs $6.2 \pm 1.5, p<0.001$ ). In unadjusted measurements of physical fitness, the groups did not differ at baseline in terms of HS and 6-MWT, but the control group performed the TUG more slowly $(p<0.05)$ (Table 2$)$.

The number of hospital days per patient during the index care episode was 11.2 (mean) in the intervention group; the number was 9.2 (mean) in the control group ( $p=0.002)$. At the 3 -month follow-up, the total number (index +3 months after discharge) of hospital days were 16.2 in the intervention group, 16.9 in the control group $(p=0.648) .{ }^{40}$

\section{Physical fitness outcomes at the 3-month follow-up}

Analyses of unadjusted continuous variables for the 0 - to 3-month change showed a significant improvement in the intervention group in all components of physical fitness. Patients in the control group significantly improved in their ability to perform the TUG, but declined in HS and 6-MWT When comparing groups, there were significant improvements in the intervention group compared with the control group in terms of HS $(p<0.001)$ and the 6-MWT $(p<0.001)$, but not for TUG ( $p=0.132)$ (Table 3 ).

After adjustment for age, gender, CCI, and the baseline value of measurement, the intervention group had significantly improved in all components of physical fitness. The patients in the control group improved in the TUG but declined in HS and the 6-MWT. Comparing groups, there were significant advantages for the intervention group in all components of physical fitness, HS $(p<0.001), 6-\mathrm{MWT}$ $(p<0.001)$, and TUG $(p=0.042)$ (Table 3$)$.

When dichotomizing the changes into the categories of decline versus stability/improvement, there were significant differences between groups for all three components of physical fitness. The intervention group declined to a lesser extent compared with the control group; $\mathrm{HS} p<0.001$, 6 -MWT $p<0.001$, TUG $p=0.003$. Figure 2 represents a visual picture of the results.

In the regression analysis, the odds ratios (ORs) showed the extent to which the outcome was influenced by the intervention; the unadjusted ORs were: HS OR 3.2 (confidence interval [CI] 95\% 1.7-6.1), 6-MWT OR 7.0 (CI 95\% 2.8-17.7), and TUG OR 2.8 (CI 95\% 1.3-5.9) (Table 4). After adjustment, the ORs were HS OR 4.4 (CI 95\% 2.2-9.1), 6-MWT OR 13.9 (CI 95\% 4.2-46.2), and TUG OR 2.5 (CI 95\% 1.1-5.4) for the tests, respectively (Table 4). 




Figure I Flowchart of data collection - physical fitness.

Notes: Flowchart completed here with information regarding participants' performance of physical fitness instruments. Copyright () 20I7. Dove Medical Press. Adapted from Ekerstad N, Karlson BW, Dahlin Ivanoff S, et al. Is the acute care of frail elderly patients in a comprehensive geriatric assessment unit superior to conventional acute medical care? Clin Interv Aging. 2017; I 2:1-9.40

Abbreviations: HS, handgrip strength; TUG, timed up-and-go; 6-MWT, 6-minute walk test.

\section{Discussion}

This study indicates that the acute medical care of frail elderly patients at a CGA unit is superior to the care at a conventional acute medical care unit when it comes to preserving physical fitness, such as HS, submaximal aerobic capacity, and functional mobility, at the 3-month follow-up.

Moreover, the present study shows that it is possible to improve physical fitness in severely frail, hospitalized 
Table 2 Baseline characteristics of the population

\begin{tabular}{|c|c|c|c|c|c|}
\hline Variable & \multicolumn{2}{|c|}{$\begin{array}{l}\text { Intervention group } \\
\text { (CGA, unit) }\end{array}$} & \multicolumn{2}{|c|}{$\begin{array}{l}\text { Control group } \\
\text { (conventional care) }\end{array}$} & $p$-value \\
\hline Age, years, mean (SD) & 206 & $85.7(5.3)$ & 202 & $85.6(5.4)$ & 0.850 \\
\hline Gender, female, n (\%) & 206 & $122(59)$ & 202 & $108(53)$ & $0.24 I$ \\
\hline Frailty screening score, mean (SD) & 206 & $3.5(0.9)$ & 202 & $3.4(0.9)$ & 0.149 \\
\hline Charlson's index score, mean (SD) & 206 & $7.4(2.1)$ & 202 & $6.2(1.5)$ & $<0.001$ \\
\hline Living alone, $\mathrm{n}(\%)$ & 206 & $139(67)$ & 202 & $132(65)$ & 0.649 \\
\hline Own living without home-help service, n (\%) & 206 & $60(29)$ & 202 & $77(38)$ & 0.055 \\
\hline Handgrip strength (kg), mean (SD) & 184 & $18.8(7.2)$ & 153 & $18.0(7.9)$ & 0.330 \\
\hline 6-MWT $(\mathrm{m})$, mean $(\mathrm{SD})$ & 147 & $146(103.4)$ & 95 & $160(100.0)$ & 0.287 \\
\hline TUG (sec), mean (SD) & 153 & $30.0(23.2)$ & 120 & $37.4(28.6)$ & 0.020 \\
\hline \multicolumn{6}{|l|}{ Reported reasons for admission, n (\%) } \\
\hline Dyspnea & 206 & $67(32)$ & 202 & $65(32)$ & \\
\hline Worsened general condition/tiredness & 206 & $48(23)$ & 202 & $43(21)$ & \\
\hline Pain & 206 & $29(14)$ & 202 & $24(12)$ & \\
\hline Fever/infection & 206 & $28(14)$ & 202 & $40(20)$ & \\
\hline Vertigo/falling & 206 & $27(13)$ & 202 & $30(15)$ & \\
\hline Others & 206 & $52(25)$ & 202 & $35(17)$ & \\
\hline
\end{tabular}

Notes: The baseline characteristics of the population divided by group, intervention group, and control group, and the main reasons that led to admission. Continuous data are presented as the mean \pm I SD. Nominal data are presented as number (\%). Copyright (C 20I7. Dove Medical Press. Adapted from Ekerstad N, Karlson BW, Dahlin Ivanoff S, et al. Is the acute care of frail elderly patients in a comprehensive geriatric assessment unit superior to conventional acute medical care? Clin Interv Aging. 2017; $12: 1-9 . .^{40}$

Abbreviations: CGA, Comprehensive Geriatric Assessment; SD, standard deviation; 6-MWT, 6-minute walk test; TUG, timed up-and-go test.

patients. The intervention group demonstrated improvements in submaximal aerobic capacity and HS, indicating that there is still rehabilitation potential. CGA management in hospital care may positively influence outcomes of great importance for the patients, such as walking ability, independence, and returning home.

To our knowledge, this is the first study which specifically and objectively evaluated CGA in terms of physical fitness. However, the results are consistent with previous research on the effects of CGA on ADL. ${ }^{34,35,37} \mathrm{ADL}$ is usually used for the evaluation of medical care for frail elderly persons using questionnaires (eg, Barthel ADL index ${ }^{48}$ or Katz index ${ }^{49}$ ), which are filled in by asking the patient, or by proxy. ${ }^{29}$ Selfreports are often used in large studies because they are easy to administer, provide few missing data, and capture the patient's own perspective. However, there is a risk of overand underestimation, recall bias, and social desirability. ${ }^{50,51}$ One review ${ }^{52}$ compiled different instruments for measuring frailty. The physical domain of the frailty syndrome was included in all the studied instruments. It was shown that the degree of frailty can be indicated in individual physical fitness tests. Tests of strength, walking ability, and endurance are most commonly used. ${ }^{14,21}$

In one study, returning home, autonomy, and walking ability were factors of great value, when elderly patients ranked the outcomes they considered most important in post-acute geriatric hospital care. ${ }^{53}$ These outcomes are all related to frailty and highlight the importance of developing interventions that may positively affect physical fitness and prevent or delay the onset of progressive disability. ${ }^{20}$

Research has shown that endurance, strength, and muscle power training can prevent disability in frail elderly people. ${ }^{54}$ In a hospital setting, a Cochrane report ${ }^{55}$ found that multidisciplinary interventions involving exercise reduced hospital length of stay, cost of hospital stay, and increased proportion of patients discharged directly home compared with usual care. Further, a meta-analysis ${ }^{56}$ showed that extra physical therapy had beneficial effects, such as improved mobility, physical activity, and quality of life, compared with a standard physical therapy program in hospitalized patients with acute or subacute conditions.

The studied CGA units work by a structured earlyrehabilitation strategy, which involves physical therapy and occupational therapy initiated immediately upon achieving physiologic stability, which continues throughout the hospital stay. Research on early rehabilitation has shown improved physical function and the intervention has been described as feasible and safe to execute. ${ }^{57}$ Many factors within the CGA concept probably influence, when it comes to preserving physical fitness. There may be several critical differences compared to conventional care, which may interact, and benefit frail elderly patients. However, the early-rehabilitation perspective including assessment, care, and educational efforts could be regarded as crucial for the prevention of functional decline. Consequently, more time was spent on physical training in these units. Good access to assistive 


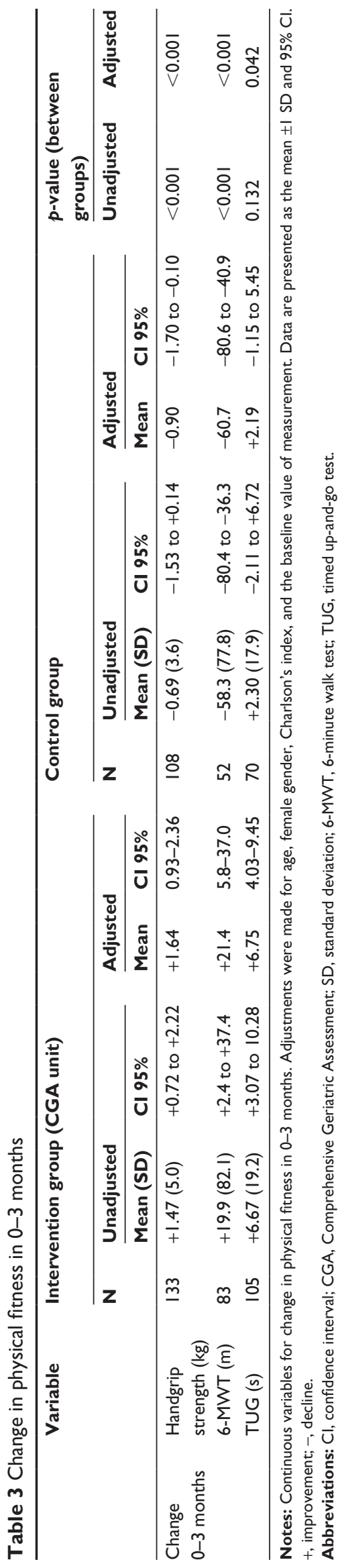

devices and team meetings, which may enable the coordination of the efforts of the team members to understand the patient's physical abilities and inspire security and encourage mobility and autonomy, are components that also may have an effect. ${ }^{16}$ However, it is still unknown exactly which components of CGA might have positive effects. It is likely that also components other than those related to physical fitness contribute to improved hospital outcomes.

Care at a CGA unit, like care at a stroke unit, is a complex multidisciplinary hospital intervention. Patients suffering from an acute stroke who are cared for at a stroke unit are more likely to survive, return home, and regain independence than those cared for in general wards. ${ }^{58}$ Langhorne et al ${ }^{59}$ studied the components that make stroke unit care effective. The results highlight the structured assessment procedures of all team members, an early-mobilization strategy, rehabilitation through a multidisciplinary team, and early planning for discharge.

The present study succeeded in including patients with severe comorbidity, disability, and cognitive impairments. It resembles the clinical reality of today's emergency medical care and the generalizability is thought to be good. The outcomes are based on measurements of different components of physical fitness with well-validated instruments. The high proportion of missing data is, however, important to consider, although it is in line with previous research including physical performance tests in hospitalized, frail, elderly patients. ${ }^{55,60}$ The walking tests in particular had a lot of missing data. In this population, it might have been advantageous to have one additional test tolerated by nonambulatory patients. Despite this, a fairly large number of participants completed the tests. In order not to lose patients to follow-up, some visits were made in the patients' homes. This made standardized performance difficult and resulted in some further dropouts.

The patients were randomized based on the availability of hospital beds, which was assumed to be the most clinically feasible method for including and evaluating patients, representative of today's emergency hospital care. Randomizing through a lottery was considered utterly difficult to implement. It is known that a lottery-randomization method is challenging when evaluating clinical practice in complex hospital health care ${ }^{61}$ and frail elderly adults with comorbidities, disabilities, and cognitive impairments are unfortunately often excluded from scientific research. ${ }^{29}$ The allocation procedure we used seems to be confirmed as random to a satisfactory extent, as most of the baseline characteristics did not differ between the groups. However, the absence of 


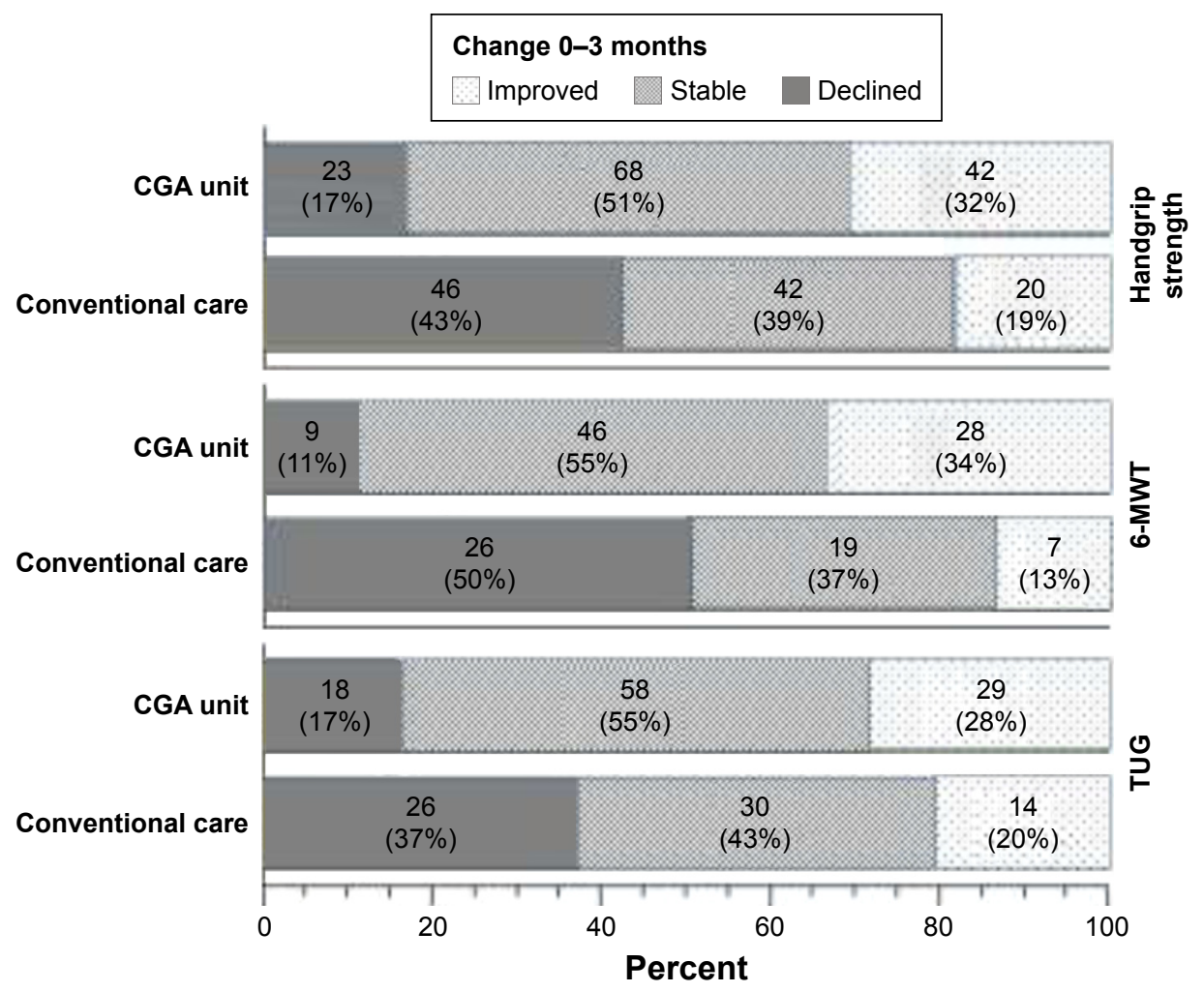

Figure 2 Changes in physical fitness in CGA unit and conventional care.

Notes: The number (\%) of patients that declined, were stable, or improved in physical fitness in CGA unit (intervention group) and in conventional care (control group). We used the change of the study population, and if changed one quartile or more, it was assumed to be a relevant change. Handgrip strength $(\mathrm{kg}):$ decline: $<-2 \mathrm{~kg}$, stable: -1 to $+2 \mathrm{~kg}$, improvement: $\geq+3 \mathrm{~kg}$. 6-MWT $(\mathrm{m})$ : decline: $<-50 \mathrm{~m}$, stable: -49 to $+23 \mathrm{~m}$, improvement: $>+24 \mathrm{~m}$. TUG (s): decline: slower than $+1.3 \mathrm{~s}$, stable: +1.2 to $-6.3 \mathrm{~s}$, improvement: faster than $-6.4 \mathrm{~s}$.

Abbreviations: TUG, timed up-and-go; 6-MWT, 6-minute walk test; CGA, Comprehensive Geriatric Assessment.

a lottery procedure constituted a potential risk of bias. In the analysis, the data were adjusted for potential differences between groups at baseline.

Another weakness is that neither patients nor staff was blinded and this could potentially have influenced a few of the outcomes. At index, neither patients nor assessors could be blinded, since the wards were located in different hospital buildings. In practice, it would have also been very difficult to blind the assessors at the 3-month follow-up.
The CGA concept might be implemented in everyday hospital health care. Future research could also focus on how components of the CGA concept might be transferred to conventional care in order to preserve physical fitness and improve the prognosis for the benefit of more hospitalized patients.

\section{Conclusion}

Medical care for acutely ill frail elderly patients at a CGA unit appears to be superior to conventional acute care

Table 4 Decline in physical fitness in 0-3 months

\begin{tabular}{|c|c|c|c|c|c|c|c|}
\hline & \multirow[t]{2}{*}{ Variable } & \multicolumn{2}{|c|}{ Intervention group } & \multicolumn{2}{|c|}{ Control group } & \multicolumn{2}{|l|}{ OR (Cl 95\%) } \\
\hline & & $\mathbf{N}$ & $\mathbf{N}(\%)$ & $\mathbf{N}$ & $\mathbf{N}(\%)$ & Unadjusted & Adjusted \\
\hline \multirow[t]{3}{*}{ Decline } & $\begin{array}{l}\text { Handgrip strength } \\
(\geq 2.0 \mathrm{~kg})\end{array}$ & 133 & $23(17.3)$ & 108 & $46(42.6)$ & $3.2(1.7-6.1)$ & $4.4(2.2-9.1)$ \\
\hline & 6-MWT ( $\geq 50 \mathrm{~m})$ & 83 & $9(10.8)$ & 52 & $26(50.0)$ & $7.0(2.8-17.7)$ & I $3.9(4.2-46.2)$ \\
\hline & TUG $(\geq 1.3 \mathrm{~s})$ & 105 & $18(17.1)$ & 70 & $26(37.1)$ & $2.8(1.3-5.9)$ & $2.5(I .1-5.4)$ \\
\hline
\end{tabular}

Notes: The 0-3 months change presented as dichotomized variables, decline versus non-decline, which denote preserved or improved physical fitness. Adjusted analyses were carried out with age, female gender, Charlson's index, and baseline value of measurement as covariates. The data are presented as number (\%), ORs, and $95 \% \mathrm{Cl}$. We found no consensus definition of minimal clinical important change for frail elderly hospitalized patients. We stipulated a definition of the rationale for these terms from a statistical viewpoint. Thus, we used the change from index to follow-up of the study population, and if decreased one quartile or more, it was assumed to be a relevant decline. Handgrip strength $(\mathrm{kg})$ : decline $>2.0 \mathrm{~kg}$. 6-MWT $(\mathrm{m})$ : decline $>50 \mathrm{~m}$. TUG $(\mathrm{s})$ : decline $>1.3 \mathrm{~s}$.

Abbreviations: 6-MWT, 6-minute walk test; TUG, timed up-and-go test; OR, odds ratio; $\mathrm{Cl}$, confidence interval. 
in terms of preserving physical fitness measured as HS, submaximal aerobic capacity, and functional mobility at 3 months follow-up.

In the acute care of frail elderly patients, more attention should focus on interdisciplinary teamwork with the emphasis on preserving physical fitness and encouraging ambulation and autonomy.

\section{Clinical implications}

This study shows that it is possible to improve physical fitness in severely frail, hospitalized patients. The CGA concept, with its focus on early rehabilitation, has been shown to benefit these patients in terms of submaximal aerobic capacity and HS. By showing there is still rehabilitation potential, targeted interventions suitable for these patients may be implemented in clinical health care, such as interdisciplinary teamwork including individualized physical therapist assessment and treatment. CGA management in hospital care may positively influence outcomes of great importance for the patients, such as walking ability and independence.

\section{Acknowledgments}

The authors wish to thank the NU Hospital Group, Department of Research and Development, for financing research time and all the coworkers within the study group for their assistance with data collection.

\section{Disclosure}

The authors report no conflicts of interest in this work.

\section{References}

1. Legramante JM, Morciano L, Lucaroni F, et al. Frequent use of emergency departments by the elderly population when continuing care is not well established. PLoS One. 2016;11(12):e0165939.

2. Aminzadeh F, Dalziel WB. Older adults in the emergency department: a systematic review of patterns of use, adverse outcomes, and effectiveness of interventions. Ann Emerg Med. 2002;39(3):238-247.

3. Hastings SN, Whitson HE, Sloane R, Landerman LR, Horney C, Johnson KS. Using the past to predict the future: latent class analysis of patterns of health service use of older adults in the emergency department. J Am Geriatr Soc. 2014;62(4):711-715.

4. Roberts DC, McKay MP, Shaffer A. Increasing rates of emergency department visits for elderly patients in the United States, 1993 to 2003. Ann Emerg Med. 2008;51(6):769-774.

5. Sager MA, Franke T, Inouye SK, et al. Functional outcomes of acute medical illness and hospitalization in older persons. Arch Intern Med. 1996;156(6):645-652.

6. Fried LP, Ferrucci L, Darer J, Williamson JD, Anderson G. Untangling the concepts of disability, frailty, and comorbidity: implications for improved targeting and care. J Gerontol A Biol Sci Med Sci. 2004;59(3): 255-263.

7. Fried LP, Tangen CM, Walston J, et al. Frailty in older adults: evidence for a phenotype. J Gerontol A Biol Sci Med Sci. 2001;56(3):M146-M156.

8. Rockwood K, Song X, MacKnight C, et al. A global clinical measure of fitness and frailty in elderly people. CMAJ. 2005;173(5):489-495.
9. Garber CE, Blissmer B, Deschenes MR, et al. American College of Sports Medicine position stand. Quantity and quality of exercise for developing and maintaining cardiorespiratory, musculoskeletal, and neuromotor fitness in apparently healthy adults: guidance for prescribing exercise. Med Sci Sports Exerc. 2011;43(7):1334-1359.

10. Caspersen CJ, Powell KE, Christenson GM. Physical activity, exercise, and physical fitness: definitions and distinctions for health-related research. Public Health Rep. 1985;100(2):126-131.

11. Ferrucci L, Guralnik JM, Simonsick E, Salive ME, Corti C, Langlois J. Progressive versus catastrophic disability: a longitudinal view of the disablement process. J Gerontol A Biol Sci Med Sci. 1996;51(3): M123-M130.

12. Clegg A, Young J, Iliffe S, Rikkert MO, Rockwood K. Frailty in elderly people. Lancet. 2013;381(9868):752-762.

13. Cruz-Jentoft AJ, Baeyens JP, Bauer JM, et al. Sarcopenia: European consensus on definition and diagnosis: report of the European Working Group on Sarcopenia in Older People. Age Ageing. 2010;39(4): 412-423.

14. Ahlund K, Ekerstad N, Oberg B, Back M. Physical performance impairments and limitations among hospitalized frail older adults. $J$ Geriatr Phys Ther. Epub 2017 Mar 1.

15. Boyd CM, Landefeld CS, Counsell SR, et al. Recovery of activities of daily living in older adults after hospitalization for acute medical illness. J Am Geriatr Soc. 2008;56(12):2171-2179.

16. Covinsky KE, Pierluissi E, Johnston CB. Hospitalization-associated disability: "She was probably able to ambulate, but I'm not sure". JAMA. 2011;306(16):1782-1793.

17. Creditor MC. Hazards of hospitalization of the elderly. Ann Intern Med. 1993;118(3):219-223.

18. Socorro Garcia A, de la Puente M, Perdomo B, Lopez Pardo P, Baztan JJ. Functional status and mortality at month and year in nonagenarians hospitalized due to acute medical illness. Eur J Intern Med. 2015;26(9): 705-708.

19. Zisberg A, Shadmi E, Gur-Yaish N, Tonkikh O, Sinoff G. Hospitalassociated functional decline: the role of hospitalization processes beyond individual risk factors. J Am Geriatr Soc. 2015;63(1):55-62.

20. den Ouden ME, Schuurmans MJ, Arts IE, van der Schouw YT. Physical performance characteristics related to disability in older persons: a systematic review. Maturitas. 2011;69(3):208-219.

21. Afilalo J, Alexander KP, Mack MJ, et al. Frailty assessment in the cardiovascular care of older adults. J Am Coll Cardiol. 2014;63(8): 747-762.

22. Buurman BM, van Munster BC, Korevaar JC, Abu-Hanna A, Levi M, de Rooij SE. Prognostication in acutely admitted older patients by nurses and physicians. J Gen Intern Med. 2008;23(11):1883-1889.

23. Cooper R, Kuh D, Hardy R; Mortality Review Group; FALCon and HALCyon Study Teams. Objectively measured physical capability levels and mortality: systematic review and meta-analysis. BMJ. 2010; 341:c4467.

24. Gale CR, Martyn CN, Cooper C, Sayer AA. Grip strength, body composition, and mortality. Int J Epidemiol. 2007;36(1):228-235.

25. Ostir GV, Kuo YF, Berges IM, Markides KS, Ottenbacher KJ. Measures of lower body function and risk of mortality over 7 years of follow-up. Am J Epidemiol. 2007;166(5):599-605.

26. Hatheway OL, Mitnitski A, Rockwood K. Frailty affects the initial treatment response and time to recovery of mobility in acutely ill older adults admitted to hospital. Age Ageing. Epub 2017 Jan 18.

27. Ng TP, Feng L, Nyunt MS, et al. Nutritional, physical, cognitive, and combination interventions and frailty reversal among older adults: a randomized controlled trial. Am J Med. 2015;128(11):1225-1236.

28. Puts MT, Toubasi S, Andrew MK, et al. Interventions to prevent or reduce the level of frailty in community-dwelling older adults: a scoping review of the literature and international policies. Age Ageing. 2017;46(3): 383-392.

29. SBU. Comprehensive Geriatric Assessment and Care of Frail Elderly. Stockholm: Swedish Council on Health Technology Assessment (SBU); 2014:221. 
30. Banerjee S. Multimorbidity - older adults need health care that can count past one. Lancet. 2015;385(9968):587-589.

31. Pilotto A, Cella A, Pilotto A, et al. Three decades of comprehensive geriatric assessment: evidence coming from different healthcare settings and specific clinical conditions. J Am Med Dir Assoc. 2017;18(2): 192.e1-192.e11.

32. Solomon DH. Geriatric assessment: methods for clinical decision making. JAMA. 1988;259(16):2450-2452.

33. Rubenstein LZ, Stuck AE, Siu AL, Wieland D. Impacts of geriatric evaluation and management programs on defined outcomes: overview of the evidence. J Am Geriatr Soc. 1991;39(9 Pt 2):8S-16S.

34. Ellis G, Whitehead MA, O’Neill D, Langhorne P, Robinson D. Comprehensive geriatric assessment for older adults admitted to hospital Cochrane Database Syst Rev. 2011;7:CD006211.

35. Baztan JJ, Suarez-Garcia FM, Lopez-Arrieta J, Rodriguez-Manas L, Rodriguez-Artalejo F. Effectiveness of acute geriatric units on functional decline, living at home, and case fatality among older patients admitted to hospital for acute medical disorders: meta-analysis. $B M J$. 2009;338:b50.

36. Prestmo A, Hagen G, Sletvold O, et al. Comprehensive geriatric care for patients with hip fractures: a prospective, randomised, controlled trial. Lancet. 2015;385(9978):1623-1633.

37. Van Craen K, Braes T, Wellens N, et al. The effectiveness of inpatient geriatric evaluation and management units: a systematic review and meta-analysis. J Am Geriatr Soc. 2010;58(1):83-92.

38. Eklund K, Wilhelmsson K, Landahl S, et al. Screening for frailty among older emergency department visitors: validation of the new FRESHscreening instrument. BMC Emerg Med. 2016;16(1):27.

39. Wilhelmson K, Duner A, Eklund K, et al. Design of a randomized controlled study of a multi-professional and multidimensional intervention targeting frail elderly people. BMC Geriatr. 2011;11:24.

40. Ekerstad N, Karlson BW, Dahlin Ivanoff S, et al. Is the acute care of frail elderly patients in a comprehensive geriatric assessment unit superior to conventional acute medical care? Clin Interv Aging. 2017;12:1-9.

41. Charlson ME, Pompei P, Ales KL, MacKenzie CR. A new method of classifying prognostic comorbidity in longitudinal studies: development and validation. $J$ Chronic Dis. 1987;40(5):373-383.

42. Mathiowetz V, Weber K, Volland G, Kashman N. Reliability and validity of grip and pinch strength evaluations. J Hand Surg Am. 1984; 9(2):222-226.

43. Alencar MA, Dias JM, Figueiredo LC, Dias RC. Força de preensão palmar em idosos com demência: estudo da confiabilidade [Handgrip strength in elderly with dementia: study of reliability]. Rev Bras Fisioter. 2012;16(6):510-514. Portuguese.

44. Podsiadlo D, Richardson S. The timed "up \& go": a test of basic functional mobility for frail elderly persons. J Am Geriatr Soc. 1991;39(2): $142-148$

45. Steffen TM, Hacker TA, Mollinger L. Age- and gender-related test performance in community-dwelling elderly people: six-minute walk test, Berg balance scale, timed up \& go test, and gait speeds. Phys Ther. 2002;82(2):128-137.
46. Guyatt GH, Sullivan MJ, Thompson PJ, et al. The 6-minute walk: a new measure of exercise capacity in patients with chronic heart failure. Can Med Assoc J. 1985;132(8):919-923.

47. Zelada MA, Salinas R, Baztan JJ. Reduction of functional deterioration during hospitalization in an acute geriatric unit. Arch Gerontol Geriatr. 2009;48(1):35-39.

48. Wade DT, Collin C. The Barthel ADL index: a standard measure of physical disability? Int Disabil Stud. 1988;10(2):64-67.

49. Katz S, Ford AB, Moskowitz RW, Jackson BA, Jaffe MW. Studies of illness in the aged. The index of ADL: a standardized measure of biological and psychosocial function. JAMA. 1963;185:914-919.

50. Kasper JD, Chan KS, Freedman VA. Measuring physical capacity. J Aging Health. 2017;29(2):289-309.

51. Portney LG, Watkins MP. Foundations of Clinical Research: Applications to Practice. Vol 2. Prentice Hall: Upper Saddle River, NJ, USA; 2000.

52. de Vries NM, Staal JB, van Ravensberg CD, Hobbelen JS, Olde Rikkert MG, Nijhuis-van der Sanden MW. Outcome instruments to measure frailty: a systematic review. Ageing Res Rev. 2011;10(1): 104-114.

53. Kus S, Muller M, Strobl R, Grill E. Patient goals in post-acute geriatric rehabilitation - goal attainment is an indicator for improved functioning. J Rehabil Med. 2011;43(2):156-161.

54. Cadore EL, Pinto RS, Bottaro M, Izquierdo M. Strength and endurance training prescription in healthy and frail elderly. Aging Dis. 2014;5(3): $183-195$.

55. de Morton NA, Keating JL, Jeffs K. Exercise for acutely hospitalised older medical patients. Cochrane Database Syst Rev. 2007;1: CD005955.

56. Peiris CL, Taylor NF, Shields N. Extra physical therapy reduces patient length of stay and improves functional outcomes and quality of life in people with acute or subacute conditions: a systematic review. Arch Phys Med Rehabil. 2011;92(9):1490-1500.

57. Kosse NM, Dutmer AL, Dasenbrock L, Bauer JM, Lamoth CJ. Effectiveness and feasibility of early physical rehabilitation programs for geriatric hospitalized patients: a systematic review. BMC Geriatr. 2013;13:107.

58. Stroke Unit Trialists Collaboration. Organised inpatient (stroke unit) care for stroke. Cochrane Database Syst Rev. 2013;9:CD000197.

59. Langhorne P, Pollock A; Stroke Unit Trialists Collaboration. What are the components of effective stroke unit care? Age Ageing. 2002;31(5): 365-371.

60. Martin-Ponce E, Hernandez-Betancor I, Gonzalez-Reimers E, Hernandez-Luis R, Martinez-Riera A, Santolaria F. Prognostic value of physical function tests: hand grip strength and six-minute walking test in elderly hospitalized patients. Sci Rep. 2014;4:7530.

61. Bakker FC, Olde Rikkert MG. Hospital care for frail elderly adults: from specialized geriatric units to hospital-wide interventions. Interdiscip Top Gerontol Geriatr. 2015;41:95-106.
Clinical Interventions in Aging

\section{Publish your work in this journal}

Clinical Interventions in Aging is an international, peer-reviewed journal focusing on evidence-based reports on the value or lack thereof of treatments intended to prevent or delay the onset of maladaptive correlates of aging in human beings. This journal is indexed on PubMed Central, MedLine,
CAS, Scopus and the Elsevier Bibliographic databases. The manuscript management system is completely online and includes a very quick and fair peer-review system, which is all easy to use. Visit http://www.dovepress. com/testimonials.php to read real quotes from published authors. 